\title{
UNIVERSUM
}

$10.4067 /$ So718-23762021000200363

\section{EL REPARTO DE LO SENSIBLE EN LA TRANSPARENCIA DEL TIEMPO, DE LEONARDO PADURA FUENTES}

\author{
The distribution of the sensible in Leonardo Padura Fuentes' La transparencia del tiempo
}

\section{Lis García-Arangor ${ }^{\mathrm{iD}}$}

${ }^{1}$ Doctorado en Literatura Latinoamericana.Universidad de Concepción, Chile.

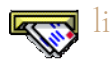

lisigar@gmail.com

\section{RESUMEN}

El artículo propone indagar, a partir de la propuesta teórica de Jacques Rancière, en la noción del reparto de lo sensible en la novela La transparencia del tiempo (2018), del escritor cubano Leonardo Padura. En el mismo se asume la perspectiva de análisis textual para detectar los agentes del reparto de lo sensible y los regímenes de igualación literaria en la obra.

PALABRAS CLAVE: Leonardo Padura; La transparencia del tiempo; reparto de lo sensible; regímenes de igualación literaria; Jacques Rancière.

\section{ABSTRACT}

The article proposes to investigate, from the theoretical proposal of Jacques Rancière, the notion of the distribution of the sensible in the novel La transparencia del tiempo (The transparency of time) (2018), by Cuban writer Leonardo Padura. It assumes the perspective of textual analysis to detect the agents of the distribution of the sensible and the regimes of literary equalization in the work. KEYWORDS: Leonardo Padura; La transparencia del tiempo; sharing of the sensible; regimes of literary equalization; Jacques Rancière. 


\section{INTRODUCCIÓN}

A meses de arribar a los 500 años de La Habana, donde las huellas de la desigualdad social se acrecientan cada día, Leonardo Padura publica la novela La transparencia del tiempo (2018). El autor propone una ficción donde se bifurcan dos líneas argumentales: de un lado, la investigación de un objeto religioso desaparecido en la Cuba del $20{ }_{4}$ (con el protagonismo, por novena vez en sus obras, del detective Mario Conde); y del otro, una serie de personajes vinculados al objeto y cuya historia se remonta al pasado, a la época colonial.

El texto comienza con Conde, a una semana de cumplir 6o años, mientras conversa por teléfono con Bobby, un antiguo compañero del preuniversitario de La Víbora. Roberto Roque Rosell (el nombre completo del amigo) le propone al detective un misterio: el robo de la efigie negra de Nuestra Señora de La Vall, reliquia proveniente de una remota ermita catalana de los Pirineos. En la búsqueda, como resulta típico en las novelas de Padura, el protagonista emprende un viaje por los trasfondos de la ciudad; muestra y redescubre dos Habanas que parecen antagónicas y subyacentes: la una, como el espejo de un país agrietado, pestilente por el peso del tiempo y el cansancio histórico; la otra, perfumada, prepotente, que se yergue y observa con indiferencia a los de abajo. Una Habana donde se acumula la pobreza. Otra Habana con destellos de riquezas. Dos Habanas unidas y distantes. Dos Habanas que evocan el fin de la utopía igualitaria socialista y los abismos que separan a los ricos y los pobres.

El enfoque de La(s) Habana(s) de Padura ofrece una mirada opuesta a los principios ideológicos y estéticos que promulga el discurso oficial del Estado cubano; el acto denota un posicionamiento político del autor (en el amplio sentido de la frase) desde el terreno literario. El escritor propone una radiografía crítica de la realidad, un movimiento que se remonta a sus primeras novelas policiales (agrupadas en la tetralogía de Las cuatro estaciones) y que mantiene durante su trayectoria. La revisión de los cánones del género lo lleva a centrar su interés en denunciar ciertos aspectos de la historia pasada cubana, como las secuelas de la Guerra de Angola, el narcotráfico, las consecuencias de la represión a los intelectuales cubanos y a los homosexuales, los casos de corrupción en las altas esferas del estado, el aumento de la marginalidad y de la delincuencia, y la pérdida de valores que se vive en la isla. Las cuatro estaciones, por ejemplo, destaca precisamente por dirigir la mirada del lector hacia el lado oscuro de esa otra realidad que para Padura es la literatura. Ya que lo que se abordaba como realidad en el policial revolucionario era "el rostro superficial, simulado, que esconde otras zonas cuidadosamente ocultas o veladas" (Uxó, 2006, p. 66). 
En la novela La transparencia del tiempo se refleja cómo en el contexto del año 2014 el tejido social cubano se ha dilatado; en un país donde antes había igualdad de posibilidades, a pesar de los escasos recursos, crece la diferenciación. En esta ocasión, el análisis del autor se centra en la pobreza extrema que se intenta invisibilizar en la sociedad. El escritor de ficciones policiacas lo consigue no solo al contar los eventos en torno de la virgen, sino también al incorporar al relato una historia que -como asegura Giorgio Agamben- sugiere un estado de excepción ${ }^{\mathrm{I}}$ en la comunidad. Y esa fragmentación de mundo la reescribe a partir de personajes anónimos, oscuros, marginales y sin voz.

Padura se vale de la figura jurídica del estado de excepción para presentar en su universo diegético la trama de los sin papeles, de aquellos migrantes del oriente cubano que pretenden asentarse en la capital. Estas personas no se rigen por la misma seguridad jurídica del resto de los ciudadanos. Sus derechos permanecen en cuestión en la medida que se encuentran fuera de la Ley. Tal y como se contempla en el Decreto Ley 217 de 1997, las migraciones internas realizadas hacia la ciudad de La Habana se regulan y penalizan en Cuba. De acuerdo con la normativa a los cubanos provenientes de otras regiones del país se les prohíbe domiciliarse, residir o convivir con carácter permanente y sin autorización en La Habana.

La vida en los asentamientos de los migrantes, conocidos popularmente como "llega y pon", se rige bajo la "forma legal de aquello que no puede tener forma legal" (Agamben, 2003, p. 24). Mediante la fórmula del estado de excepción, ${ }^{2}$ el autor visibiliza el espacio sin ley que se construye en la comunidad, un sitio descrito en la novela como "lo más cercano al Viejo Oeste que habían visto en sus vidas y en su ciudad: un territorio sin ley. O con su propia ley" (Padura, 2018, p. I26).

La visibilización de la pobreza extrema y del estado de excepción se consigue en La transparencia del tiempo a través del reparto de lo sensible referido por Jacques Rancière (2009); precisamente, el objetivo principal de este artículo consiste en explorar y describir, desde lo político, la noción de reparto de lo sensible que propone la novela. Para ello, se asume la perspectiva de Rancière centrada en el análisis textual.

\footnotetext{
r El estado de excepción es "el dispositivo original a través del cual el derecho se refiere a la vida y la incluye dentro de sí por medio de su propia suspensión, entonces una teoría del estado de excepción es condición preliminar para definir la relación que liga y al mismo tiempo abandona lo viviente en manos del derecho" (Agamben, 2003, p. 24).

2 "Cuando se habla de estado de excepción, y de que hay ámbitos donde las leyes no valen, lo que también se señala es que cada vez sirven menos los grandes principios que inspiraban a los estados-nación, los que regían la política internacional. Donde no hay normas fijas, ni principios que acepten todos, lo que se impone es la gestión, el resolver los problemas de la manera que sea, y la policía se convierte en la figura central. A la policía se le permite hacer cosas que la ley no autoriza porque se entiende que se enfrenta con situaciones excepcionales. Pero cuando todo forma parte de un estado de excepción, se generalizan los métodos policiales" (Agamben, en Rojo, 2 de febrero de 2004).
} 


\section{AGENTES DEL REPARTO DE LO SENSIBLE}

Rancière (2009) define reparto de lo sensible como un "sistema de evidencias sensibles que al mismo tiempo hace visible la existencia de un común y los recortes que allí definen los lugares y las partes respectivas" (p. 9). Según esta lógica, el conflicto de toda actividad política radica en distinguir qué es palabra y qué no para retrasar las fronteras de lo sensible. Desde el lejano tiempo de Aristóteles, se considera al hombre "un animal político porque es un animal literario, que se deja desviar de su destino "natural' por el poder de las palabras" (p. 50); ser político que posee la palabra, que puede separar lo justo de lo injusto. La capacidad política, además, depende de una frontera de lo sensible.

La literatura contemporánea, de la cual Leonardo Padura forma parte, decide un reparto de lo sensible, un recorte de mundo en base a un cuestionamiento ético, estético y político. El reparto de lo sensible se vincula con la política de la literatura, "en tanto que literatura es ese recorte de los espacios y los tiempos, de lo visible y lo invisible, de la palabra y el ruido", e "[i]nterviene en la relación entre prácticas, entre formas de visibilidad y modos de decir que recortan uno o varios mundos comunes" (Rancière, 20II, pp. I6-I7). El análisis textual de La transparencia del tiempo evidencia ese recorte de espacios y tiempos y de palabra y ruido. En la novela, amparado en un narrador omnisciente en tercera persona o extradiegético -aunque en los diálogos las narraciones aparecen escritas en primera persona-, el autor reparte lo sensible en tres líneas fundamentales: una Habana deteriorada, un asentamiento que es tan pobre que ni siquiera tiene nombre y personajes marginales.

Esa otra Habana cada vez más degradada por la pobreza y el abandono histórico, es la que Mario Conde (2018) se empeña en encontrar "bajo las capas de suciedad, años y precariedades de todas las especies y géneros" (p. 6o). Padura (2018) retrata la miseria humana compactada por el paso del tiempo mediante el recorrido de Conde por la ciudad.

Los rostros de las gentes, de las cuales recibía miradas cargadas de recelo, eran el espejo de sus almas, y sus almas el fruto de su medio: la precariedad acendrada, multiplicada en los últimos veinte años de una crisis que tronchó el posible sueño de muchos de encontrar una mejoría en sus vidas. Lo peor era que, como aquel falansterio, había cientos en la ciudad, donde vivían miles de personas que ya no esperaban nada de lo que encontraban, como las garrapatas afanadas en sacar el último aliento de los perros famélicos sobre los cuales él había pasado. (p. 6I)

De esta manera se valida la tesis de Rancière (20II) de que "la literatura es indisolublemente una ciencia de la sociedad y la creación de una mitología nueva" (p. 39). En la búsqueda de la virgen negra, Mario Conde arriba al asentamiento ubicado en San Miguel del 
Padrón, donde personas, que llegaron a La Habana buscando mejores condiciones de vida, viven en una situación material desfavorable. En la novela, Conde bautiza este lugar como 'el mundo de los invisibles, las catacumbas de las catacumbas'. Para entrar al asentamiento, el Conde tuvo que localizar a Candito para que lo contactara con el evangélico Oriol, pues a ese territorio no podía cruzar cualquiera sin una recomendación previa. Así se evidencia en el diálogo de los compañeros del preuniversitario:

Mira, averíguame con tu gente si uno de tus colegas conoce a alguien de tu iglesia en ese barrio. Y si puede darnos un contacto. Tú ya sabes cómo funciona eso, Rojo: no es que me vaya a pasar nada, pero si llego allí y comienzo a preguntar por un tipo del que ni siquiera sé el nombre verdadero, nadie me va a dar la luz. (Padura, 20I8, p. 8I)

En la travesía del Conde la llegada al asentamiento fue como trasladarse a otro universo, como si atravesara un hoyo negro.

El hedor malsano del hacinamiento y la pobreza les salió al paso y los removió con el impacto de la fetidez inconfundible, agresiva. Era una mezcla dolorosa del extravío de las esperanzas, los efluvios aportados por las aguas negras fluyentes a través de zanjas descubiertas, los aceites fritos y refritos, los vertederos pútridos ambientados por millones de moscas zumbonas, los chiqueros improvisados donde se revolcaban los cerdos en el fango y en la mierda. (Padura, 20I8, p. I28)

Con semejante descripción se sitúa a la población desplazada de la urbe; se denota tanto su estatus económico como social. Padura enfoca una dimensión diferente del espacio y el tiempo. Traslada al lector a un territorio donde habitan personajes indocumentados, ocultos, que el Estado pretende invisibilizar e ignorar. Ese pedazo de Cuba era "un país dentro y a la vez un país fuera" (Padura, 20I8, p. I57). En este relato, se considera el componente geográfico como un elemento de significación, pues de ahí se desprende el lugar desde 'dónde se reparte lo sensible'. El hecho de que La transparencia del tiempo haya sido escrita en La Habana y que parte de la trama principal se sitúe en un asentamiento denota un posicionamiento político. Padura no solo ubica a sus personajes en el espacio de los solares en Centro Habana, donde viven el Murciélago, Candito o René Águila, sino que se sale de las habituales descripciones de La Habana en ruinas para llegar a la periferia física y social del asentamiento, un gesto que los iguala con sus paisanos marginales del centro. Ese otro mundo, situado en la periferia social, geográfica y literaria, se narra desde la perspectiva de Mario Conde, una óptica que ahora parece centralista (aunque previamente, al compararlo con el confort de los barrios más adinerados -Playa, El Vedado, Siboney- su suburbio de La Víbora parecía marginal).

A los individuos que viven en el asentamiento -como Ramiro Gómez, más conocido como Ramiro la Manta, y Oriol el Santo- Padura les ofrece un reconocimiento público mediante la 
escritura. El narrador interviene en el reparto de lo sensible en la medida que visibiliza lo invisible, que le da voz a los sin voz, que dice y hace perceptible el mundo que habita -en este caso el mundo de los asentamientos ilegales-. En el diálogo que establece Conde con su amigo el Conejo se identifica dicho reparto:

- ¿Qué coño es esto, Conde? - preguntó el Conejo, que miraba a uno y otro lado como si no creyese lo que sus ojos le mostraban.

-La infravida -soltó el Conde su posible definición del ambiente circundante-. Es otra vida. Pero también es real.

- ¿Esto es vida? -dudo el Conejo.

-Sí, Conejo, aunque quieran hacerla invisible -dijo Conde. (Padura, 2018, p. 153)

En el asentamiento, Padura (2018) presenta a personajes que son desde "maleantes y negociantes de cualquier especie hasta [...] albañiles [...] Pero si gente como esa quiere vivir aquí, tiene que aceptar las reglas de juego y ser lo que es fuera del barrio. Esto es territorio apache" (p. I25). Las prácticas existentes en el asentamiento permiten la visibilidad de ese sector poblacional y de concebir otros modos de vivir, otras leyes de convivencia. A muchos de los habitantes del asentamiento, las autoridades les impiden trabajar por carecer de documentos para residir en La Habana; otros, deciden no ofrecer su fuerza laboral al Estado por el ínfimo salario que perciben. De tal manera, el asentamiento se transforma y mantiene diferentes tipos de experiencia colectiva.

Aquí se vende todo lo que alguien pueda imaginar: carne de res, películas pornográficas, materiales de construcción. Hay prostitutas profesionales y ocasionales, y droga, por supuesto, aunque se cuidan mucho con eso porque saben que allá fuera -indicó hacia la ciudad, el otro planeta- se ponen molestos con ese tema. (Padura, 2018, p. I25)

Por la pluralidad de actividades humanas en el asentamiento se construye un mundo sensible común. Los diferentes trabajos que realizan los habitantes contribuyen al reparto de lo sensible, al determinar diferentes maneras de ser y de ocupaciones distribuidas en otro espacio subalterno. Por tanto, el reparto de lo sensible en una sociedad dada define qué personas pueden ser admitidas o no en un lugar. El asentamiento es un espacio mudo, ilegitimo que no representa a La Habana en su totalidad, "privado del soplo que anima y transporta la palabra viviente" (Rancière, 2009, p. I4). Sin embargo, la reproducción de esa forma de vida ilegal y que algunos de los asesinatos y actos delictivos ocurran en el asentamiento forma parte de lo cotidiano.

Una situación semejante a los "llega y pon" -la de instalarse y sobrevivir en un estado de excepción, en el vacío legal- se percibe en la representación literaria de los tratantes de arte. Tal es el caso de Bobby, "mercader que se dedica a la compra y venta de objetos valiosos, obras de arte, joyas, cosas caras" (Padura, 20I8, p. I8). En La transparencia del tiempo, Bobby es presentado como un 
personaje con influencia y voz dentro del mundo del arte clandestino de La Habana, pero tiempo atrás por su condición homosexual fue víctima de las presiones de vivir en una sociedad "empecinada en regir todos los comportamientos éticos, políticos, sociales, y en reprimir, con rigor y hasta con saña, cualquier manifestación de diferencia" (Padura, 20I8, p. I8). Bobby fue expulsado de la universidad por "una grave desviación ideológica y moral, incompatible con la actitud de un joven universitario revolucionario" (homosexualidad) (Padura, 20I8, p. II3). Incluso Conde arrastra las secuelas de las normas sociales de la sociedad revolucionaria; cuando Bobby lo visita en su casa, "antes de cerrar la puerta, mira hacia uno y otro lado de su calle. No le gustaba demasiado la idea de que la gente del barrio lo viera meter en su casa a aquel personaje" (Padura, 2018, p. I4).

El reparto de lo sensible define, según las competencias de las personas, la pertenencia o la exclusión del espacio común. En este proceso, la posición socioeconómica y cultural resulta definitoria. En el universo diegético de La transparencia del tiempo (que se enmarca en el resto de obras donde Padura incluye a Mario Conde), ${ }^{3}$ el reparto de lo sensible comienza desde el propio personaje protagónico. El detective, tras abandonar su empleo en la Policía Nacional Revolucionaria, conoce al exingeniero Jorge Reutilio Casamayor, (alias Yoyi el Palomo) en la obra La neblina del ayer. Desde entonces, Yoyi se convierte en el socio comercial del Conde, quien para sobrevivir sucumbe al dominio del mercado. El expolicía del Estado se dedica a la compra y venta de libros, y en ocasiones ejerce como detective privado. El diálogo con la arquitecta Karla Choy valida la nueva profesión del Conde:

\footnotetext{
-Dime, ¿qué clase de policía tú eres?

-Más o menos como tú en tu negocio: policía por cuenta propia. No soy de los que mete presa a la gente... Más bien las busco cuando andan perdidas. De algo tengo que vivir...

-Me gusta eso: eres el primer detective privado cubano desde 1959... ¡Eres un rey, yo lo sabía!... Tengo una psicología... Ah, ven acá, ¿aquí hay licencia para ser detective por cuenta propia?

-No que yo sepa... Soy clandestino... (Padura, 2018, p. I79).
}

En esta confesión, Mario Conde se iguala con los sin papeles de los asentamientos en la medida que vive fuera de la ley, que ejerce su trabajo en el terreno del estado de excepción mencionado por Agamben, a contrapelo de las normas impuestas por el estado (la licencia para el trabajo privado de los detectives) y las reglas del negocio callejero de La Habana. El Conde opera como un anomal ${ }^{4}$ que media entre los dispares escenarios del reparto de lo sensible en la obra.

\footnotetext{
3 Novelas donde aparece el personaje Mario Conde: Pasado Perfecto (1991), Vientos de cuaresma (1994), Máscaras (I997), Paisaje de otoño (1998), Adiós Hemingway (200I), La neblina del ayer (2002), La cola de la serpiente (20II), Herejes (2013), y La transparencia del tiempo (2018).

4 Para Deleuze y Guattari (2002) "lo anomal es una posición o un conjunto de posiciones con relación a una multiplicidad". El adjetivo anomal resalta las cualidades y sitúa las posiciones de un individuo excepcional en la manada. Se ha podido
} 
Otros personajes como Yuniesky Bonilla, alias el Murciélago, por su defecto congénito en la vista, son presentados y visibilizados por Padura. El desempleo del "pichón de vampiro" -apodo que alude a sus años en prisión por hurtos continuados-, perpetúa su pertenencia a un territorio degradado, acompañado de negros, putas, lúmpenes, proletarios, santeros y ñáñigos. El lugar donde vive el Murciélago se ubica en Centro Habana, y se representa como "una especie de colmena en donde se hacinaban decenas de familias" (Padura, 2018, p. 58).

La descripción de los negociantes clandestinos de arte no resulta menos ilustrativo: René Águila, "el más despiadado e inescrupuloso" (Padura 20I8, p. 68); Elizardo Soler, quien "más sabe en Cuba del mercado de arte [...] y saca de debajo de la tierra lo que le pidas" (Padura, 20I8, p. 44); la china Karla Choy, "culta, hábil, persistente [...] La mejor en este negocio" (Padura, 20I8, p. 46); Bobby o incluso el mismo Palomo, quienes reconfiguran e ilustran actividades económicas invisibilizadas en el discurso oficial.

\section{REGIIMENES DE IGUALACIÓN LITERARIA}

El concepto de democracia en el ámbito de la literaturas supone "un nuevo reparto de lo sensible, de una relación nueva entre el acto de la palabra, el mundo que éste configura y las capacidades de aquellos que pueblan ese mundo" (Rancière, 20II, p. 29). Desde esa noción, la obra de Leonardo Padura evidencia un afán de democratización de la palabra y el mundo representado; existe una apuesta de democratización en el pensar del detective Mario Conde y una pugna contra el totalitarismo que lo envuelve. La democracia literaria pretende ampliar la línea de lo sensible. Según Rancière (20II), se compone de tres regímenes de expresión que definen tres formas de igualdad: igualdad de los temas y la disponibilidad de toda palabra o de toda frase para construir el tejido de cualquier vida; la democracia de las cosas mudas; y la democracia molecular de los estados de cosas sin razón.

Son tres «democracias» [...]; tres formas con las que se trabaja para elaborar el paisaje de lo visible, modos de descifrar ese paisaje y de diagnosticar sobre lo que los individuos y las colectividades han hecho y pueden hacer. [...] tres políticas en tensión entre ellas. [...] La política de la literatura

señalar que la palabra -anomal, adjetivo caído en desuso, tenía un origen muy diferente de -anormal: a-normal, adjetivo latino sin sustantivo, califica lo que no tiene regla o que contradice la regla, mientras que, -anomalía, sustantivo griego que ha perdido su adjetivo, designa lo desigual, lo rugoso, la asperidad, el máximo de desterritorialización (p. 249).

${ }^{5}$ La literatura "define una distancia [...] a la escena política democrática. [...] A esta puesta en escena democrática, la literatura le opone otra política, cuyo principio es el de [...] abandonar [...] la palabra enunciada por las voces sonoras para poder descifrar los testimonios que la sociedad misma da a leer, para exhumar aquellos que ésta descarta sin quererlo ni saberlo en los bajos fondos. Al ruidoso escenario de los oradores se le opone el viaje por los mundos subterráneos, que conservan la verdad oculta" (Rancière, 20II, pp. 39-40). 
es la colisión de esas políticas. [...] su crítica se hace ante todo mediante el juego de esas tensiones. (p. 48-49)

De acuerdo con el primer régimen de la igualdad de los temas, Padura consigue cambiar la visibilidad del mundo (mediante la interpretación), en el sentido de una reinterpretación de un género literario (policial revolucionario), ${ }^{6}$ ya que posibilita una nueva mirada hacia la realidad de Cuba, acción que ofrece nuevas posibilidades para "ejercitarse sobre el paisaje común" (influir la realidad). La democratización de los objetos mudos -segundo régimen de expresión- se constata en los escritores, que al igual que Padura, cultivan el género policial y tienen una fascinación por el detalle. Uno de los objetos que más habla en La transparencia del tiempo es la virgen negra. El autor potencia el carácter místico a través del símbolo de la virgen, la cual adquiere un poder espiritual y religioso que producto de la fe puede tener un efecto real en los individuos de las comunidades.

Alojarse en las nuevas viviendas, construidas con lo inimaginable, constituye una visión de conjunto, anti-representativa. Con cartones, pedazos de madera, tiras de zinc y pisos de tierra apisonada habían levantado las primeras casas fundadoras del asentamiento ilegal. El "llega y pon" se convierte en un asunto de índole política en cuanto "revoca la doble política inherente a la lógica representativa" (Rancière, 2009, p. I6), y se manifiesta en "aquellos aliens" que viven en el lugar y operan con "códigos encriptados" (Padura, 2018, p. 125). Los materiales de construcción constituyen en símismos objetos mudos que hacen visible la pobreza de la vida de los pobladores.

Los locales aparecían cubiertos con los más disímiles materiales encargados de proteger a sus moradores de la lluvia y el sol: desde techos de zinc o madera hasta cubiertas de papel impermeable, llegando al extremo precario de coberturas de tela embreada o pedazos de nailon, fijados con algún trozo de piedra o viga de hierro. Las leyes del urbanismo, la arquitectura y hasta la de la gravedad resultaban desconocidas en aquel enjambre de aposentos miserables, creando una distribución caótica y asfixiante. (Padura, 20I8, pp. I2I-I22)

Objetos mudos recurrentes en La transparencia del tiempo resultan las bolsas de nylon blanco sucio que lleva un vagabundo. Conde, al escuchar el roce del plástico de las bolsas en el cemento, reconoce la presencia de este ser: “AAhí estaba el hombre invisible!" (Padura, 20I8, p. 19I). Otros objetos que denotan un significado son los accesorios del vestuario. El oro es un material que prefieren los tratantes de arte en La Habana. Ramiro tiene dientes dorados y una "gruesa cadena de oro"; Yoyi, "sobre el promontorio óseo, refulgía una pesada medalla [...], una medalla con la imagen de la Virgen" (Padura, 2018, p. 20).

\footnotetext{
${ }^{6}$ El reflejo de la realidad cubana en la literatura policial revolucionaria resulta maniqueo y su objetivo -apoyado desde las instituciones culturales y editoriales- resulta ideologizante: reafirmar la razón del proceso revolucionario cubano frente al "enemigo imperialista y los apátridas internos" y a partir del discurso político-ideológico, los autores policiacos cubanos "se lanzaron a la creación de una literatura apologética, esquemática" (Padura, 200o, p. 153). Cultivaban un realismo socialista que "tenía mucho de socialista pero poco de realismo" (Padura, 2000, p. I53).
} 
La preferencia de marcas como las gafas Ray Ban de Yuniesky Bonilla o la ropa que vestía René, la rata -"un polo de Lacoste de un exultante rojo tomate, unos jeans blancos, impolutos, adornados con una chapilla metálica que recalcaba su filiación a la escudería de Calvin Klein, y unas sandalias de cuero opaco, obra inconfundible de Birkenstock" (Padura, 2018, p. 68)- describen el poder adquisitivo de esos personajes. Los negociantes de arte en su manera de expresarse y de vestirse advierten gustos similares que les permiten coexistir en el dominio de un mejor estatus económico en Cuba. Desde una posición ilegal, tienen el poder de admitir a quienes quieran en su mundo. Su estatus les permite darse determinados beneficios y protegerse entre sí. Por ejemplo, Yoyi, al ganar tanto dinero con sus tratos comerciales, recompensa al Conde y, de vez en cuando, "por caminos que no resultaran onerosos, lo salvaba de la miseria. De la fuácata, como ellos solían llamarle al estado e inopia en que casi siempre vivía el policía renegado" (Padura, 20I8, p. 22).

La metodología detectivesca del Conde constituye el tercer régimen de igualación: democracia molecular de los estados de cosas sin razón. De acuerdo con los argumentos filosóficos de Deleuze, "la igualdad novelesca no es la igualdad molar de los temas democráticos, sino la igualdad molecular de los microsucesos, de las individualidades que no son individuos sino diferencias de intensidad, cuyo ritmo puro cura toda fiebre a la sociedad" (Rancière, 20II, p. 48). Los métodos heterodoxos del Conde de confiar en premoniciones -por ejemplo, cuando le pica debajo de la tetilla izquierda-, la intuición y los presentimientos para resolver los casos, se pueden enumerar como un estado de cosas sin razón. Se valida en la metodología empleada durante su rutina investigativa, que cada vez "decía funcionar con corazonadas, prejuicios, premoniciones" (Padura, 20I8, p. 2II).

En La transparencia del tiempo, el reparto igualitario de lo sensible se establece en el asentamiento como "principio de re-partición político de la experiencia común" (Rancière, 2009, p. i6) en la medida en que se reparten el nuevo territorio que ocupan y establecen nuevas formas de convivencias, con base en la experiencia común en otras regiones de Cuba. Los asentados no pueden acceder al servicio de la Empresa Eléctrica - por no poseer contratos legales del Instituto de la Vivienda, ni documentos que respalden su estancia en La Habana-, como tampoco a la libreta de abastecimiento, cartilla mediante la que se compran alimentos subsidiados por el gobierno.

Con el agua habían tenido más suerte: alguien de la Dirección de Recursos Hidráulicos se había apiadado de ellos y habían bajado una acometida desde la tubería de alimentación más cercana y distribuido conexiones en algunos puntos del asentamiento, desde donde los habitantes del lugar sacaban líneas hacia sus viviendas: gracias a ello un día sí y otro no les llegaba agua corriente por unas cuatro o cinco horas. (Padura, 20I8, p. I24) 
Las formas de vida de los asentados se entremezclan en un espacio reducido y opuesto al que se vive en la urbe capitalina. Los habitantes del lugar, al delimitar su territorio del dominio legal del Estado, realizan una imitación como "principio normativo de inclusión" (Rancière, 2009, p. 23). Las formas de normatividad definen las condiciones en las que las imitaciones pueden ser reconocidas y apreciadas en el interior del sitio elegido para vivir y pueden ser "buenas o malas, adecuadas o inadecuadas: repartos de lo representable y de lo irrepresentable" (Rancière, 2009, p. 23). Padura, al identificar el espacio y el tiempo de la vida de los habitantes del asentamiento, propone una nueva forma de copresencias heterogéneas en la comunidad. Reconstruye un universo ficcional a partir de la visión de los otros, de los detalles de su vida cotidiana y revoca las jerarquías establecidas por el Gobierno cubano al vincular las diferentes clases sociales en Cuba, que van de un extremo a otro, por sus características totalmente opuestas.

La novela reparte lo sensible en la medida que permite hablar a los testigos mudos de la historia común. Al apropiarse del dispositivo lingüístico, desvía al lector hacia temáticas no abordadas anteriormente por los autores del género policial cubano (como la delincuencia, la marginalidad antisocial) y a personajes del bajo mundo ignorados por el discurso oficial. De tal manera, el autor reconoce y ofrece la palabra (el referido límite de lo político desde los tiempos aristotélicos) a quienes quedan fuera del reparto de lo sensible; a aquellos migrantes perjudicados por el Decreto Ley 217/97 que los priva de derechos.

En La transparencia del tiempo, se presentan las fronteras económicas y sociales que existen en la Cuba contemporánea. El autor lo demuestra al sumergirse en las 'catacumbas de las catacumbas', lugares en plena expansión en la capital y demás ciudades principales. A través de la obra, puede reconocerse a toda la sociedad cubana -en particular a sus áreas ignoradas-gracias al viaje de Conde por los bajos fondos; dicha empresa permite la igualación, al menos en el utópico territorio ficcional, de personajes que viven en los extremos de un mismo tiempo histórico y un mismo espacio geográfico.

\section{REFERENCIAS}

Agamben, Giorgio (2003). Estado de excepción. Homo sacer II, I. Adriana Hidalgo editora. Deleuze, Gilles y Guattari, Félix (2002). Mil mesetas. Capitalismo y esquizofrenia. PRE-TEXTOS.

Padura, Leonardo (2000). Modernidad, potmodernidad y novela policial. Ediciones UNIÓN. Padura, Leonardo (2018). La transparencia del tiempo. Tusquets Editores. 
Rancière, Jacques (2009). El reparto de lo sensible. Estética y política. Ediciones LOM.

Rancière, Jacques (20iI). Política de la literatura. Libros del Zorzal.

Rojo, José Andrés (2 de febrero de 2004). Entrevista: Giorgio Abamben, Filósofo: "El estado de excepción es hoy la norma". El País. https://cutt.ly/XRoTQ 36

Uxó, Carlos (2006). The Detective Fiction of Leonardo Padura Fuentes. Manchester Metropolitan University Press. 